\title{
Predicting the risk of depression among adolescents in Nepal using a model developed in Brazil: the IDEA Project
}

\author{
Rachel Brathwaite ${ }^{1}$ Thiago Botter-Maio Rocha ${ }^{2,3} \cdot$ Christian Kieling $^{2,3} \cdot$ Kamal Gautam $^{4} \cdot$ Suraj Koirala ${ }^{4}$ \\ Valeria Mondelli ${ }^{5}$ Brandon Kohrt ${ }^{4,6} \cdot$ Helen L. Fisher $^{1}$ (i)
}

Received: 13 September 2019 / Accepted: 29 February 2020 / Published online: 12 March 2020

(c) The Author(s) 2020

\begin{abstract}
The burden of adolescent depression is high in low- and middle-income countries (LMICs), yet research into prevention is lacking. Development and validation of models to predict individualized risk of depression among adolescents in LMICs is rare but crucial to ensure appropriate targeting of preventive interventions. We assessed the ability of a model developed in Brazil, a middle-income country, to predict depression in an existing culturally different adolescent cohort from Nepal, a lowincome country with a large youth population with high rates of depression. Data were utilized from the longitudinal study of 258 former child soldiers matched with 258 war-affected civilian adolescents in Nepal. Prediction modelling techniques were employed to predict individualized risk of depression at age 18 or older in the Nepali cohort using a penalized logistic regression model. Following a priori exclusions for prior depression and age, 55 child soldiers and 71 war-affected civilians were included in the final analysis. The model was well calibrated, had good overall performance, and achieved good discrimination between depressed and non-depressed individuals with an area under the curve (AUC) of 0.73 (bootstrap-corrected 95\% confidence interval 0.62-0.83). The Brazilian model comprising seven matching sociodemographic predictors, was able to stratify individualized risk of depression in a Nepali adolescent cohort. Further testing of the model's performance in larger socio-culturally diverse samples in other geographical regions should be attempted to test the model's wider generalizability.
\end{abstract}

Keywords Adolescence $\cdot$ External validation $\cdot$ LMIC $\cdot$ Mental health $\cdot$ Prediction model $\cdot$ Risk calculator

\section{Introduction}

Major depressive disorder (MDD) is a leading underlying cause of disability worldwide [1]. MDD increases the future risk of developing chronic diseases including diabetes mellitus, cardiovascular disease, and stroke [2], and is a major contributor to death by suicide globally [1]. MDD commonly emerges during adolescence [3,4], yet despite receiving treatment, many adolescents experience a relapse of depression [5]. Consequently, functional impairment and

Brandon Kohrt and Helen L. Fisher contributed equally to this work.

Electronic supplementary material The online version of this article (https://doi.org/10.1007/s00787-020-01505-8) contains supplementary material, which is available to authorized users.

Helen L. Fisher

helen.2.fisher@kcl.ac.uk

Extended author information available on the last page of the article increased risk of suicide continue into adulthood [6]. Given that by age 18 , lifetime prevalence of MDD is approximately $11 \%[7,8]$, this reinforces the need for research to prevent the onset of depression in the adolescent period to facilitate early intervention and avoid long-term health and socioeconomic disadvantage [9]. Therefore, it is important to ascertain which adolescents are most at risk of developing depression to effectively target interventions to prevent its onset [10].

Factors such as family psychiatric history [11], childhood maltreatment [12], female gender [13], chronic pain or illnesses [14], are associated with an increased risk of depression among adolescents. However, these risk factors have mainly been considered in isolation and knowledge about the combination of factors that best predicts the onset of depression in this critical developmental period is limited. One method for estimating combined risk of future events is prediction modelling. Advantages of this method over standard regression approaches include prediction of new or future risks of an outcome at the 
individual rather than group level, while accounting for a wide combination of predictors simultaneously [15]. Examples of widely used prediction models include: the Framingham Risk Score which is utilized in primary care settings to predict individualized future risk of developing a first cardiovascular event in 10 years among individuals free of cardiovascular disease [16], and the Gail model used to predict 5-year and lifetime risk of invasive breast cancer in healthy women [17]. The development of models to predict individualized risk of future psychiatric health outcomes is expanding (though mainly limited to predicting psychosis), but is still in its infancy for depression and other mental illnesses [18, 19].

Models that predict MDD have conventionally been derived in adult not adolescent populations [20-23], and limited to patients who have experienced chronic or lifethreatening medical conditions [24-27] or to predict recurrence of depression [28, 29]. The Chicago Adolescent Risk Assessment is one known model developed in a US adolescent population to predict 1-year risk of depression in adolescents [30]. However, this model was not externally validated and overall few researchers have externally validated depression prediction models in relatively similar but socio-culturally or geographically diverse populations to test the model's predictive accuracy [21, 22].

Our group has recently developed a multivariable prediction model to predict individualized risk of developing depression in late adolescence using data from the population-based 1993 Pelotas Birth Cohort in south Brazil (Pelotas model) [31]. Although the Pelotas model performed well in predicting depression in the cohort from Brazil, a middle-income country, its ability to accurately predict depression among adolescents in resource poor, low-income settings is unknown. Nepal presents an opportunity to test this because it is considered to be one of the least developed countries globally, with $\sim 15 \%$ of the population below the income poverty line [32]. Additionally, Nepal has suffered an 11-year (1996-2006) Civil War (also known as the "People's War") between the Communist Party of Nepal (Maoist) and the government of Nepal, resulting in the killings of over 17,000 people [33]. Nepal comprises a large youth population ( $>50 \%$ of the population younger than age 25 ) transitioning into adulthood [34]. During the war, several thousand children were drafted by the Maoist People's Army to be soldiers, sentries, spies, cooks, porters, and messengers $[35,36]$. Due to the negative impact to health, social well-being, and financial stability imposed during the war, one consequence has been a high prevalence of adolescent depression observed in Nepal [37], leading to poor quality of life [37], and high levels of suicidal ideation [38]. However, not all adolescents exposed to this environment developed depression, and we do not know which Nepali adolescents are at higher risk of developing depression in the future.
Therefore, we assessed the Pelotas model's ability to predict depression in late adolescence in an existing adolescent cohort from Nepal, to evaluate the performance of the model in a socio-culturally different lower income setting.

\section{Methods}

\section{Description of study setting and recruitment of study cohort}

We used quantitative data from a longitudinal study of child soldiers and matched civilians in Nepal [38-41]. The study was conducted by Transcultural Psychosocial Organization Nepal (TPO Nepal). At the end of the war, some former child soldiers who returned home participated in reintegration programs sponsored by UNICEF in eight districts (Dhankuta, Sindhuli, Makwanpur, Chitwan, Rupandehi, Kapilbastu, Dhading, and Dolakha) of Nepal [40]. The programs included formal education, vocational skill training, apprenticeships, or business development skill training to enhance their income-generating abilities [42]. This project identified and recruited a Nepali cohort of former child soldiers, using lists of names of child soldiers provided by UNICEF-associated human rights organizations.

Former child soldiers were recruited into the study if they were younger than 18 years old at study enrolment, served as a soldier for at least 1 month during the war, and if consent was granted by their caregiver and oral assent by the child. The first 30 names of former child soldiers enrolled in reintegration programs from each of the eight districts were invited to participate in the study. A cohort of waraffected civilian children, matched on age, sex, ethnicity, and educational level, who were not associated with armed forces and groups (civilian children) were recruited from school records. Civilian status was confirmed via interviews and name checking on the child soldiers' lists. None of the participants had previously received psychosocial support before joining the study.

The Nepali adolescent cohort was aged 11-18 years at baseline (wave 1) in 2007 ( $N=516$ ), comprising 258 former child soldiers who returned home from the war, matched with 258 war-affected civilian adolescents [40]. This cohort was followed up 1 year later in 2008 (wave 2: $N=456$ ), and 5 years later in 2012 (wave 3: $N=290$ ) [39]. Due to the high illiteracy rate among the study population, trained researchers administered questionnaires to former child soldiers and civilian children to collect data on a range of characteristics during the child soldiers' longitudinal research. 


\section{Outcome assessment}

The outcome in our analysis was of the presence of clinically relevant depression at age 18 or older. Depression was assessed using the Nepali version of the Depression Self Rating Scale (DSRS) for children at all time points [43, 44]. This tool utilized self-reported ratings of 'Mostly', 'Sometimes', or 'Never' for 18 items used to measure depression symptoms in the past week. Scores can range from 0 to 36 , with a cut-off score of 14 and above considered as indicating clinical depression in the Nepali population [area under the curve $(\mathrm{AUC})=0.82$, sensitivity $=0.71$, specificity $=0.81]$ [44].

\section{Data harmonization}

For this analysis, an a priori decision was made to select predictors that most closely matched those in the existing prediction model derived in the 1993 Pelotas birth cohort in Brazil [31, 45]. The 11 predictors in the Pelotas model were 'biological sex', 'skin colour', 'drug use', 'school failure', 'social isolation', 'fight involvement', 'relationship with mother', 'relationship with father', 'relationship between parents', 'childhood maltreatment', and 'ran away from home'. For the 'skin colour' Pelotas variable, we used caste/ethnicity in Nepal, with low caste (Dalit) considered the at-risk group in comparison to high caste (Brahman/ Chhetri) and ethnic minority (Janajati) groups. This categorization was based on identification of low caste as a risk factor in multiple prior studies in Nepal [37, 46]. More details on the availability of matching predictors and how they were assessed in the Pelotas and Nepali samples are provided in Table S1.

\section{Selection of Nepali sample to be included in prediction modelling analysis}

Because the Nepali cohort was not a birth cohort and adolescents were different ages (11-18 years) at baseline (wave 1 ), we assessed exposure to potential risk factors if they occurred before age 18 and evaluated the outcome of depression at wave 3 when participants were aged 18 or older. Adolescents were, therefore, included in the analysis if they met the following criteria: younger than 18 at wave 1 or 2 ; did not have evidence of depression at wave 1 or 2 ; aged 18 or older at wave 3; and assessed for depression at all waves. Adolescents were excluded if they were: lost-to-follow-up at waves 2 or 3 ; older than 18 at wave 1 or 2 ; younger than 18 at wave 3; or had evidence of depression at waves 1 or 2 (see Fig. S1 for a flowchart explaining the selection of the final sample included in the analysis). The final sample included in the analysis comprised 126 adolescents ( 71 civilians and 55 former child soldiers).

\section{Data analysis}

Data management was performed using STATA, version 15.1 [47]. All models were implemented using the R Statistics software, version 3.5.3 [48]. The data analysis comprised several steps. First, the linear predictor from the penalized logistic regression model [which used penalized maximum likelihood estimation (PMLE)], developed in the Pelotas cohort (Pelotas model) was recalculated using only the same predictor variables that were also available in the Nepali dataset. This model was then applied in the Nepali dataset to assess the adequacy of its performance (standard external validation). Second, due to differences in the prevalence of depression in late adolescence between the Pelotas and Nepali cohorts, the model intercept became mis-calibrated. The Pelotas model intercept (baseline risk) was, therefore, adjusted through recalibration so that the average predicted probability was equal to the observed frequency of depression in the Nepali cohort (adjusted external validation) [49]. Third, to account for different strengths of predictors between the Pelotas and the Nepali cohorts, the regression coefficients for the predictors were re-estimated in the Nepali dataset instead of the Pelotas dataset and a new refitted linear predictor was obtained (refitted model). This represents the performance of the model if the regression coefficients from the Pelotas cohort were the same as the regression coefficients in the Nepali cohort [50].

\section{Sensitivity analyses}

As a sensitivity analysis, we explored whether the Pelotas model's ability to predict depression differed according to child soldier status, given that being a child soldier increased the risk of depression among Nepali youth [37]. To do so, we fitted a logistic regression model which comprised the linear predictor derived from the Pelotas model, the child soldier variable, and their interaction term.

Net reclassification improvement (NRI) methods were also used to assess improvement in the model performance by assessing to what extent adolescents were correctly reclassified into high- and low-risk depression categories by the inclusion of child soldier status in the Pelotas model [51].

\section{Evaluation of model performance}

The predictive performance of the Pelotas prediction model externally validated in the Nepali dataset was evaluated by assessing: (1) calibration - the agreement between observed depression in the Nepali dataset and predicted probability of depression from the Pelotas model; and (2) discrimination-how well the prediction model can differentiate those with depression from those without depression [52]. Model 
calibration was evaluated visually via calibration plots. We referred to the values of (1) calibration-in-the-large-comparison of the average of all predicted probabilities with the average observed depression cases in the Nepali dataset, with values closer to zero indicating better model performance; and (2) calibration slope-measure of agreement between observed depression and predicted risk of depression for all predictors in the Nepali dataset (a perfect model has a calibration slope of 1 ; [53]). A Chi-square test to measure unreliability of the calibration accuracy was performed to assess whether there was a statistically significant difference between the model predictions and the $45^{\circ}$ line [53]. We assessed discrimination using the receiver operator characteristic (ROC) curve. An area under the curve (AUC) value of 0.5 indicates that a model does not discriminate better than chance, while 1 indicates that a model discriminates perfectly. Guidelines suggest AUC values over 0.7 represent a good model whereas values $\geq 0.8$ indicate strong models [54]. Overall, model performance was assessed using the Brier score [52]. This calculates the average squared difference between the predicted probability of depression and the actual probability of depression [55]. A Brier score of $0 \%$ represents a perfect model.

Note, unlike traditional regression models, penalized regression models do not permit interpretation of coefficients for the individual predictors included in the model. This is because applying a penalty to reduce over-fitting to the data introduces bias into the regression estimates resulting in the coefficients no longer being reflective of true population-level associations with depression risk. Moreover, the purpose of prediction models is to identify the combination of predictor variables that together most accurately predict an individual's risk of developing depression rather than considering the role of each predictor separately. Therefore, only the overall model performance statistics are provided in this paper.

\section{Results}

After the data harmonization, there was $13.2 \%$ of the original Pelotas model's information lost due to the unavailability of 4 of the 11 predictors in the Nepali dataset (see Table S1). All included participants had complete data on the outcome and all seven predictors included in the model ('biological sex', 'caste/ethnicity', 'drug use', 'school failure', 'social isolation', 'fight involvement', and 'childhood maltreatment').

The sample included in the final analysis comprised 126 Nepali adolescents. One third of the sample was female (34.1\%), one-fifth was low caste (18.3\%), and $43.7 \%$ were former child soldiers. A substantial proportion experienced probable childhood maltreatment $(47.7 \%)$, while a smaller proportion experienced severe childhood maltreatment
(27.8\%). School failure was low (14.3\%) among the Nepali adolescents and a smaller minority showed characteristics of being socially isolated (5.6\%). No one admitted to using drugs, and behavioural problems such as getting into fights was reasonably uncommon (13.5\%). The prevalence of depression at age 18 or older at wave 3 in the Nepali cohort was $19.8 \%$ (25/126 scored 14 or more on the DSRS, scores ranged from 0 to 22 ) comprising 18 (72\%) women and 15 (60\%) former child soldiers, while in the Pelotas cohort, the point prevalence of depression at age 18 was $3.1 \%$. There was no difference in the gender, caste/ethnicity, and child soldier status between participants included and excluded from the final analysis (see Table S2).

\section{External validation in Nepali cohort}

When applied to the Nepali cohort, the predictive model showed reasonable capacity to discriminate between individuals who developed depression in late adolescence and those who did not (AUC $=0.73$; Bootstrap-corrected $95 \%$ CI 0.62-0.83; Fig. 1a). Initially, the model was not well calibrated, but this improved when the intercept was corrected (calibration-in-the-large reduced from 2.44 to 0.00 ) (Table 1) (Fig. 2a, b). The $p$ value from the Chi-square test for unreliability of the calibration accuracy was not significant $\left(\chi^{2}=0.2702, p=0.874\right)$. This affirms the model achieved good calibration since there was no statistically significant difference between the model predictions and the ideal $45^{\circ}$ line. The overall performance of the model also improved slightly after adjustment of the intercept as indicated by a reduction in the Brier score from 0.18 to 0.14 (Table 1). The final refitted model's discriminative capacity AUC was 0.83; bootstrap-corrected 95\% CI 0.74-0.91 (Fig. 1b). Its overall performance, as expected, was also better (Brier score reduced to 0.12) (Table 1).

\section{Sensitivity analysis findings}

There was no statistically significant interaction observed between child soldier status and the linear predictor derived from the Pelotas model in predicting depression in the Nepali cohort ( $p$ value $=0.802$ ). The overall NRI result was also not significant for inclusion of child soldier status in the model (NRI $=0.0205$, lower CI -0.0829 , upper CI 0.1519; standard error $=0.0603$ ). Moreover, there was only a negligible change in the AUC value (0.01) between the Pelotas model in the Nepal cohort $(\mathrm{AUC}=0.73)$ and the model with child soldier status included $(\mathrm{AUC}=0.74)$. This indicates that the new model containing child soldier status as a predictor did not improve the overall Pelotas model's predictive capacity to estimate those at higher risk of future depression. The proportion of depressed cases that moved up through the categories from low risk to high risk when the new model 
Fig. 1 ROC curve for a the Pelotas model externally validated in Nepal data [area under the curve $(\mathrm{AUC})=0.73$; bootstrap-corrected $95 \%$ confidence interval 0.62-0.83], and $\mathbf{b}$ the Pelotas model refitted in the Nepal data $(\mathrm{AUC}=0.83$; bootstrap-corrected $95 \%$ confidence interval 0.74-0.91). The $y$-axis shows the true positive rate: the proportion of adolescents correctly identified with depression. The $x$-axis shows the false positive rate: the proportion of adolescents who were wrongly identified as having depression. The grey diagonal line represents a model that discriminates the same as chance
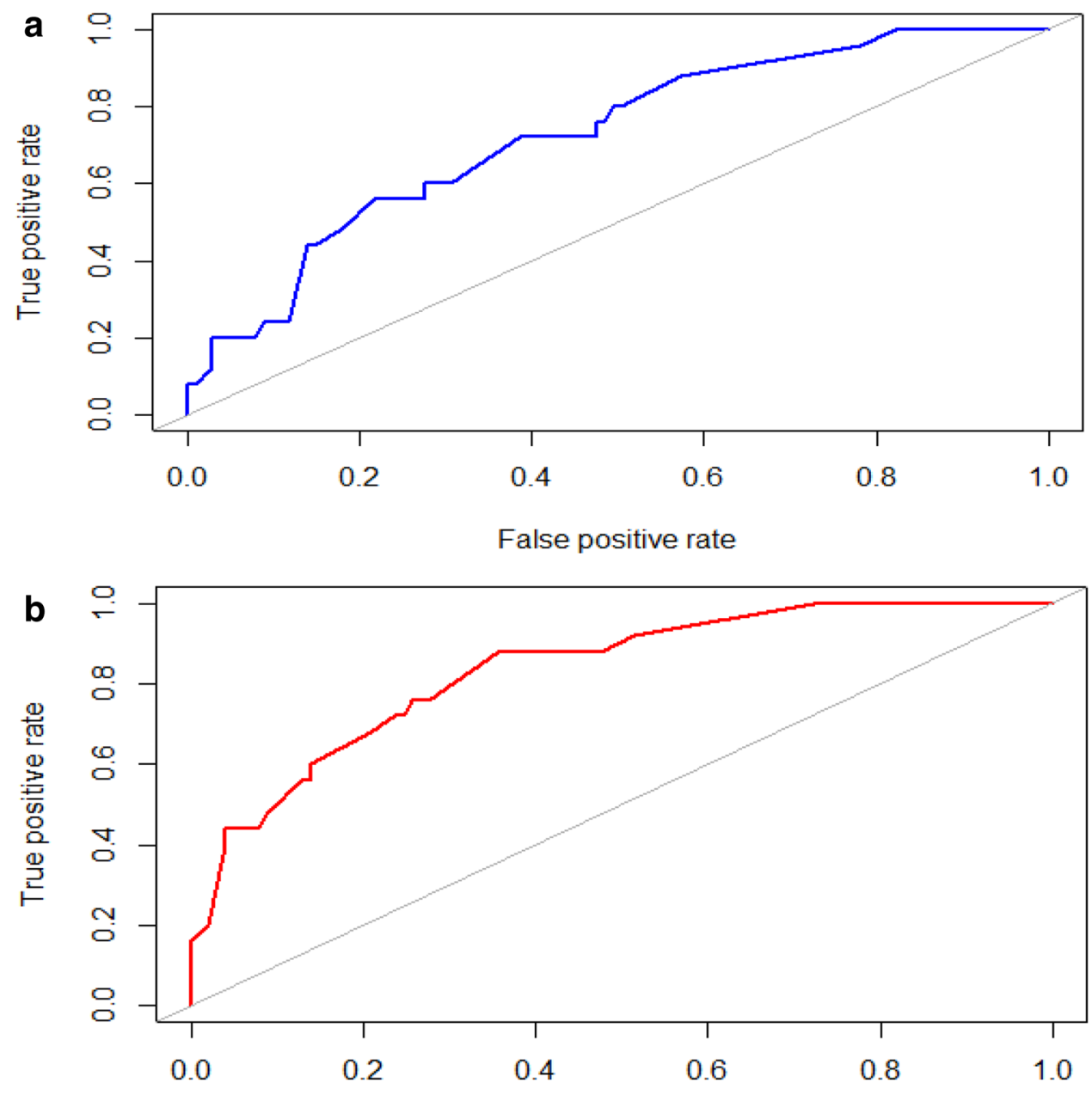

False positive rate with child soldier status included was used was not significant (NRI+ $=0.0800$, lower CI 0.0000, upper CI 0.2083; standard error $=0.0534)$. However, the proportion of nondepressed cases that moved down the categories from high risk to low risk was significant (NRI- $=-0.0594$, lower CI - 0.1100, upper CI -0.0098). This implies that including child soldier status in the model may be better at reducing false positives for future risk of depression in Nepal, but not false negatives.

\section{Discussion}

\section{Summary of the main findings}

The novel predictive model developed in an adolescent cohort in Pelotas, Brazil, comprising seven individual and social predictors (gender, caste/ethnicity, childhood maltreatment, school failure, fights, drug use, and social isolation) was able to acceptably predict clinically relevant depression in late adolescence in a Nepali adolescent cohort free of depression. The model demonstrated a good ability to differentiate adolescents who did and did not develop depression. This means that a randomly selected adolescent with depression had a higher risk prediction score than a randomly selected adolescent without depression. After adjustment, the model predictions were better aligned with the observed prevalence of depression in Nepal. There was also good overall performance despite the small sample size, and how socio-culturally divergent the Nepali adolescent population was compared to the Brazilian cohort. Moreover, the model was able to predict depression similarly for both child soldiers and war-affected civilian adolescents in Nepal inferring its ability to predict future risk of depression amongst individuals without evidence of previous depression from somewhat different backgrounds.

The Pelotas model's ability to differentiate between adolescents who did or did not develop depression in Nepal (AUC $=0.73$ ) was comparable to the widely used Framingham risk score which predicts whether men $(\mathrm{AUC}=0.76)$ 
Table 1 Comparison of performance metrics for the Pelotas model when externally validated in the Nepali cohort compared to its apparent and internal validation in the Pelotas cohort

\begin{tabular}{|c|c|c|c|c|c|c|}
\hline \multirow[t]{2}{*}{ Model assessment } & \multirow{2}{*}{$\begin{array}{l}\text { Performance meas- } \\
\text { ures }\end{array}$} & \multicolumn{2}{|l|}{ Pelotas cohort } & \multicolumn{3}{|l|}{ Nepali cohort } \\
\hline & & Apparent validation & Internal validation & $\begin{array}{l}\text { Standard external } \\
\text { validation }\end{array}$ & $\begin{array}{l}\text { Adjusted external } \\
\text { validation }\end{array}$ & Refitted model \\
\hline $\begin{array}{l}\text { Overall perfor- } \\
\text { mance or model } \\
\text { fit }\end{array}$ & Brier score & 0.03 & 0.03 & 0.18 & 0.14 & 0.12 \\
\hline Discrimination & AUC (95\% CI) & $0.78(0.73-0.82)$ & $0.71(*)$ & $0.73(0.62-0.83)$ & $0.73(0.62-0.83)$ & $0.83(0.74-0.91)$ \\
\hline \multirow[t]{2}{*}{ Calibration } & $\begin{array}{l}\text { Calibration-in-the- } \\
\text { large }\end{array}$ & 0.00 & 0.02 & 2.24 & 0.00 & 0.00 \\
\hline & Calibration slope & 1.26 & 1.00 & 1.18 & 1.18 & 1.50 \\
\hline
\end{tabular}

$86.8 \%$ of the original Pelotas' model's information was available for external validation due to the availability of only 7 of the 11 predictors in the Nepali dataset

Apparent validation: the performance of the Pelotas model in the development data (in the Pelotas cohort)

Internal validation: the performance in the Pelotas cohort after controlling for over-optimism, using bootstrapping techniques

External validation (standard): the performance when applied to the Nepali sample

External validation (adjusted): the performance in the Nepali sample after the intercept was corrected

Refitted model: regression coefficients for the Pelotas model re-estimated in the Nepali dataset

AUC: area under the curve of the receiver operating characteristic (presented as a proportion). The AUC is identical to the C-statistic for binary outcomes

Brier score: quadratic scoring rule that combines calibration and discrimination-a Brier score of 0 represents a perfect model

Calibration-in-the-large reflects the model intercept. Calibration slope of a perfect model is equal to 1

*Unable to derive $95 \%$ confidence interval for the internal validation model

and women $(\mathrm{AUC}=0.79)$ will develop cardiovascular disease [16]. It is also similar to a model developed to predict onset of major depression among adults in the US general population $(\mathrm{AUC}=0.75)$ [23]. The Pelotas model has previously been assessed in two independent cohorts from highincome countries (the United Kingdom and New Zealand) with adolescents who had no evidence of previous depression [31]. The discriminative ability in the Nepali cohort was slightly better $(\mathrm{AUC}=0.73)$ than its performance in the UK (AUC $=0.59)$ and New Zealand $(\mathrm{AUC}=0.63)$ [31]; however, the $95 \%$ CI suggests the true area under the curve for the Nepali cohort can lie between 0.62 and 0.83 . Nonetheless, this suggests that the Pelotas adolescent depression risk model may work better in other LMIC contexts than in high-income countries. However, further testing with suitable adjustments in a range of other LMICs is required before it can be utilized on a global scale.

\section{Limitations}

When a model is externally validated in a different independent cohort, one of the main challenges is data harmonization. Although, we were able to closely match 7 of the 11 predictors in the Nepali dataset, differences in data collection instruments used in Nepal and Brazil resulted in imperfect harmonization. For instance, the Nepali childhood maltreatment composite variable lacked appropriate measures for 'separation from family', 'feeling hated' or 'unwanted by close family members' so we were not able to capture entirely the same construct. There were also differences in how depression was assessed, with a cut-off on a symptom measure (DSRS) being used to indicate clinically relevant depression in the Nepali cohort rather than a diagnosis of depression as was used in the Pelotas cohort. Nonetheless, this cut-off on the DSRS has been clinically validated in Nepal and shown to discriminate well between Nepali youth with and without a diagnosis of depression [44]. Furthermore, differences in the prevalence and reporting of risk factors may differ by context. For example, drug use was completely denied by Nepali adolescents $(0 \%$ in Nepal vs $62.4 \%$ in Pelotas). In Nepal, admitting to using drugs could have reduced the chance of child soldiers being enrolled into one of the UNICEF-sponsored reintegration programs and thus tends to be underreported. Additionally, the question used to measure 'drug use' did not elucidate the inclusion of alcohol, marijuana, or tablets. Hence respondents probably assumed it to mean illicit drugs only, leading to nondisclosure of the use of legal substances. Moreover, we were unable to exclude individuals who had an IQ $<70$ or who had not gone through puberty as was done in the original Pelotas analysis.

The Nepali adolescent cohort was not a birth cohort, hence it is unlikely to be representative of the entire Nepali adolescent population in 2007. The cohort also comprised 

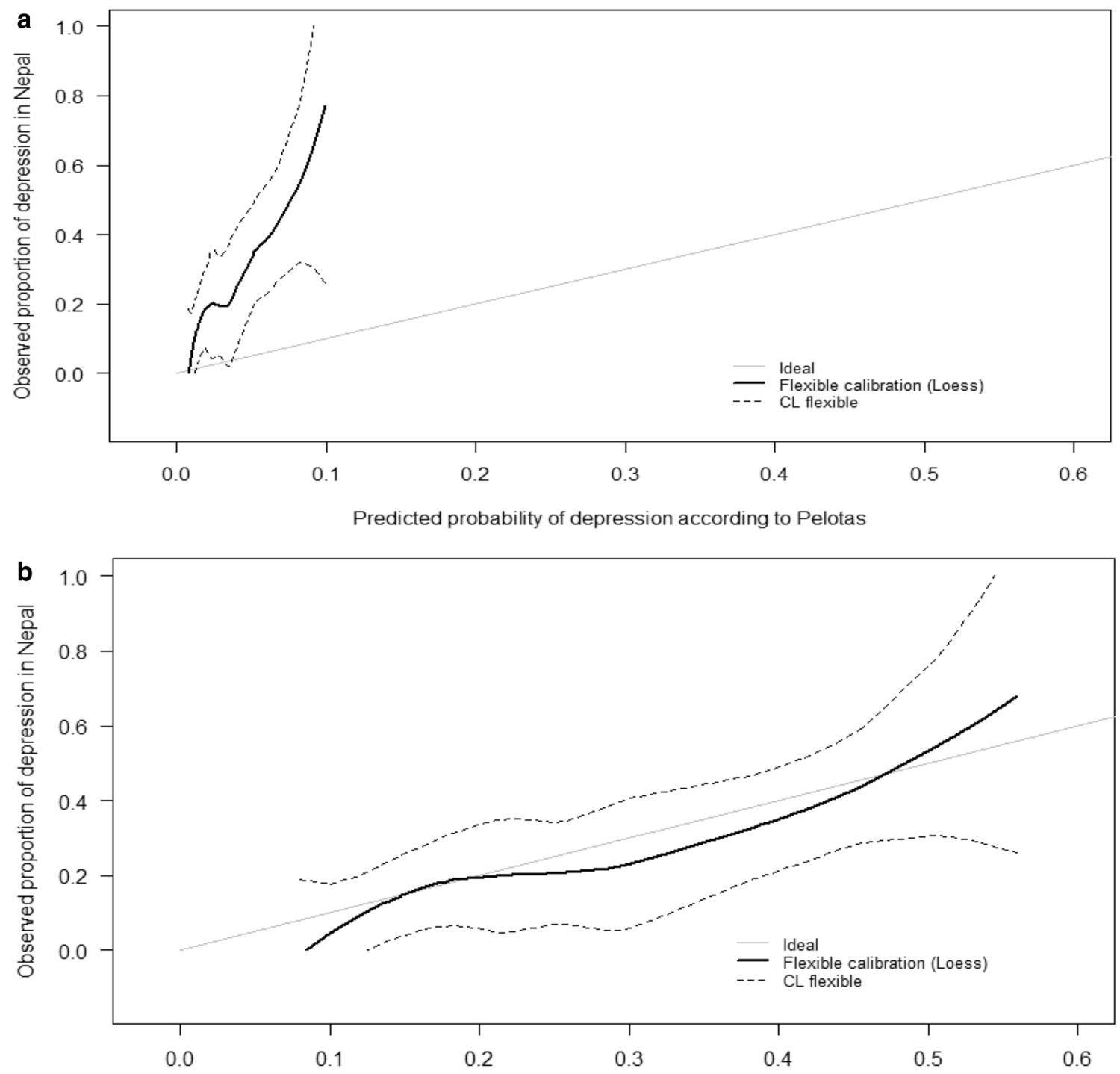

Predicted probability of depression according to Pelotas

Fig. 2 Calibration plot for a the Pelotas model externally validated in the Nepal dataset, and $\mathbf{b}$ when the intercept of the Pelotas model was adjusted. Graphical display of model predictions (as depicted by the black flexible calibration line with $95 \%$ confidence limits around the model predictions as dashed lines) on the $x$-axis and observed propor-

a sample of former child soldiers of the Maoist army who voluntarily returned home after the war matched with civilian children. Hence, those who did not return home or child soldiers elsewhere may have different risks for depression [37]. The Pelotas sample was a birth cohort and risk factors were assessed if they occurred at age 15 . Conversely, the cross-sectional cohort design in Nepal, meant that not all adolescents in Nepal had the same assessment age for some predictors. This along with the reasonably high lossto-follow-up rate $(43.8 \%$ at wave 3 ) created challenges in determining the 'at risk' period. Finally, the performance of the model should be interpreted with caution due to the tion of depression in the Nepali cohort on the $y$-axis. The calibration plots show how well the model predictions align with the observed rate of depression in Nepal. Perfect agreement between the predictions and the observed rate are indicated by perfect alignment on the ideal line

potential for estimates to be imprecise due to the relatively small sample size.

\section{Implications}

In Nepal, less than $1 \%$ of the Nepal government's healthcare budget is spent on mental health and $>90 \%$ of the population in need of mental health services have no access to treatment [56]. Identification and early intervention for adolescents at higher risk of depression could potentially reduce the high suicide rates [57] and prevent morbidity [58] in this country. Using a tool comprising 
relatively easy-to-obtain factors to predict which adolescents are most at risk of developing depression could help target prevention initiatives.

It is also essential to conduct qualitative research with key stakeholders to gather perspectives about the feasibility and acceptability of using a depression prediction tool in Nepal. We need to advance our understanding of ways to embark upon predicting risk of depression within a culture where mental illness and experience of traumatic events are stigmatized [59]. New educational and awareness interventions that challenge social stigma towards mental health problems should thus also be considered prior to any future implementation of a risk screening tool in Nepal [60]. Moreover, careful consideration of the ethical issues surrounding the identification of adolescents at high risk of depression in low-resource settings where provision of effective interventions to prevent depression is limited is also required [61, 62].

\section{Conclusion}

A model comprising seven demographic and social predictors developed in a middle-income country was able to reasonably predict depression among adolescents in a socioculturally diverse, low-income country that was afflicted by humanitarian crises. We recommend testing the performance of the model in other adolescent cohorts from diverse contexts and geographical regions and with larger sample sizes before it is used in health, educational or social services' contexts. Further exploratory research on the inclusion of more context-specific factors in the predictive model would bring added information to its replicability and generalizability across settings.

Acknowledgements The IDEA project is funded by an MQ Brighter Futures Grant (Grant number MQBF/1 IDEA). Additional support was provided by the UK Medical Research Council (Grant number MC_PC_MR/R019460/1) and the Academy of Medical Sciences (Grant number GCRFNG\100281) under the Global Challenges Research Fund. The Nepal child soldier longitudinal research has received support from UNICEF Nepal, the HopeLab Foundation (https://www.hopelab.org, Redwood City, California, PIs: Brandon Kohrt and Carol Worthman), and the US National Institute of Mental Health (Grant number F31MH075584, PI: Brandon Kohrt). All research was implemented by Transcultural Psychosocial Organization Nepal (TPO Nepal). Dr Fisher is supported by a British Academy Mid-Career Fellowship (Grant number MD\170005). Dr Kieling is a Conselho Nacional de Desenvolvimento Científico e Tecnológico (CNPq) researcher. Dr Valeria Mondelli is supported by the Medical Research Foundation (Grant number MRF-160-0005-ELP-MONDE) and by the National Institute for Health Research (NIHR) Biomedical Research Centre at South London and Maudsley NHS Foundation Trust and King's College London. The views expressed are those of the authors and not necessarily those of the NHS, the NIHR, or the Department of Health.
Author contributions RB and HLF drafted the manuscript. TR and RB performed the analysis. BK, SK, KG designed the TPO Nepal child soldier longitudinal study and collected the data. CK, HLF, TR, and $\mathrm{RB}$ contributed to the statistical analysis revisions for the paper. All authors commented on and contributed to revisions of the paper and have read and approved the final manuscript.

\section{Compliance with ethical standards}

Conflict of interest The authors declare that they have no conflict of interest.

Ethical standards Ethical review boards of the Nepal Health Research Council, Emory University, and George Washington University approved the study. Participants over 18 years of age provided consent. For participants under 18 years of age, legal guardians provided consent, and minors provided assent. The research team obtained verbal consent or assent from all participants. This study was, therefore, performed in accordance with the ethical standards laid down in the 1964 Declaration of Helsinki and its later amendments.

Open Access This article is licensed under a Creative Commons Attribution 4.0 International License, which permits use, sharing, adaptation, distribution and reproduction in any medium or format, as long as you give appropriate credit to the original author(s) and the source, provide a link to the Creative Commons licence, and indicate if changes were made. The images or other third party material in this article are included in the article's Creative Commons licence, unless indicated otherwise in a credit line to the material. If material is not included in the article's Creative Commons licence and your intended use is not permitted by statutory regulation or exceeds the permitted use, you will need to obtain permission directly from the copyright holder. To view a copy of this licence, visit http://creativecommons.org/licenses/by/4.0/.

\section{References}

1. World Health Organization (2017) Depression and other common mental disorders: global health estimates (No. WHO/MSD/ MER/2017.2). World Health Organization, Geneva

2. Prince M, Patel V, Saxena S, Maj M, Maselko J, Phillips MR, Rahman A (2007) No health without mental health. Lancet 370:859_ 877. https://doi.org/10.1016/S0140-6736(07)61238-0

3. Burke KC, Burke JD Jr, Rae DS, Regier DA (1991) Comparing age at onset of major depression and other psychiatric disorders by birth cohorts in five US community populations. Arch Gen Psychiatry 48:789-795. https://doi.org/10.1001/archpsyc.1991.01810 330013002

4. Lewinsohn PM, Rohde P, Seeley JR (1998) Major depressive disorder in older adolescents: Prevalence, risk factors, and clinical implications. Clin Psychol Rev 18:765-794. https://doi. org/10.1016/S0272-7358(98)00010-5

5. Curry J, Silva S, Rohde P, Ginsburg G, Kratochvil C, Simons A, Kirchner J, May D, Kennard B, Mayes T, Feeny N, Albano A, Lavanier S, Reinecke M, Jacobs R, Becker-Weidman E, Weller E, Emslie G, Walkup J, Kastelic E, Burns B, Wells K, March J (2011) Recovery and recurrence following treatment for adolescent major depression. Arch Gen Psychiatry 68:263-269. https:// doi.org/10.1001/archgenpsychiatry.2010.150

6. Weissman MM, Wolk S, Goldstein RB, Moreau D, Adams P, Greenwald S, Klier CM, Ryan ND, Dahl RE, Wickramaratne P 
(1999) Depressed adolescents grown up. JAMA 281:1707-1713. https://doi.org/10.1001/jama.281.18.1707

7. Avenevoli S, Swendsen J, He J-P, Burstein M, Merikangas KR (2015) Major depression in the national comorbidity surveyadolescent supplement: prevalence, correlates, and treatment. J Am Acad Child Adolesc Psychiatry 54:37-44.e32. https://doi. org/10.1016/j.jaac.2014.10.010

8. Kessler RC, Avenevoli S, Merikangas KR (2001) Mood disorders in children and adolescents: an epidemiologic perspective. Biol Psychiatry 49:1002-1014. https://doi.org/10.1016/S0006 $-3223(01) 01129-5$

9. Saxena S, Jané-Llopis E, Hosman C (2006) Prevention of mental and behavioural disorders: implications for policy and practice. World Psychiatry 5:5-14

10. Kieling C, Adewuya A, Fisher HL, Karmacharya R, Kohrt BA, Swartz JR, Mondelli V (2019) Identifying depression early in adolescence. Lancet Child Adolesc Health 3:211-213. https:// doi.org/10.1016/S2352-4642(19)30059-8

11. Weissman MM, Berry OO, Warner V, Gameroff MJ, Skipper J, Talati A, Pilowsky DJ, Wickramaratne P (2016) A 30-year study of 3 generations at high risk and low risk for depression. JAMA Psychiatry 73:970-977. https://doi.org/10.1001/jamap sychiatry.2016.1586

12. Gerke J, Koenig AM, Conrad D, Doyen-Waldecker C, Pauly M, Gündel H, Wilker S, Kolassa I-T (2018) Childhood maltreatment as risk factor for lifetime depression: the role of different types of experiences and sensitive periods. Ment Health Prev 10:56-65. https://doi.org/10.1016/j.mhp.2018.03.002

13. Hyde JS, Mezulis AH, Abramson LY (2008) The ABCs of depression: integrating affective, biological, and cognitive models to explain the emergence of the gender difference in depression. Psychol Rev 115:291-313. https://doi. org/10.1037/0033-295X.115.2.291

14. Pinquart M, Shen Y (2011) Depressive symptoms in children and adolescents with chronic physical illness: an updated metaanalysis. J Pediatr Psychol 36:375-384. https://doi.org/10.1093/ jpepsy/jsq104

15. Moons KG, Royston P, Vergouwe Y, Grobbee DE, Altman DG (2009) Prognosis and prognostic research: what, why, and how? BMJ 338:b375. https://doi.org/10.1136/bmj.b375

16. D’Agostino RB Sr, Vasan RS, Pencina MJ, Wolf PA, Cobain M, Massaro JM, Kannel WB (2008) General cardiovascular risk profile for use in primary care: the Framingham Heart Study. Circulation 117:743-753. https://doi.org/10.1161/circulatio naha.107.699579

17. Byar DP, Gail MH, Schairer C, Brinton LA, Corle DK, Green SB, Mulvihill JJ (1989) Projecting individualized probabilities of developing breast cancer for white females who are being examined annually. J Natl Cancer Inst 81:1879-1886. https:// doi.org/10.1093/jnci/81.24.1879

18. Bernardini F, Attademo L, Cleary SD, Luther C, Shim RS, Quartesan R, Compton MT (2017) Risk prediction models in psychiatry: toward a new frontier for the prevention of mental illnesses. J Clin Psychiatry 78:572-583. https://doi.org/10.4088/ JCP.15r10003

19. Fusar-Poli P, Hijazi Z, Stahl D, Steyerberg EW (2018) The science of prognosis in psychiatry: a review. JAMA Psychiatry 75:1289-1297. https://doi.org/10.1001/jamapsychi atry.2018.2530

20. Fernandez A, Salvador-Carulla L, Choi I, Calvo R, Harvey SB, Glozier N (2018) Development and validation of a prediction algorithm for the onset of common mental disorders in a working population. Aust N Z J Psychiatry 52:47-58. https://doi. org/10.1177/0004867417704506

21. King M, Walker C, Levy G, Bottomley C, Royston P, Weich S, Bellón-Saameño JÁ, Moreno B, Švab I, Rotar D, Rifel J, Maaroos
H-I, Aluoja A, Kalda R, Neeleman J, Geerlings MI, Xavier M, Carraça I, Gonçalves-Pereira M, Vicente B, Saldivia S, Melipillan R, Torres-Gonzalez F, Nazareth I (2008) Development and validation of an international risk prediction algorithm for episodes of major depression in general practice attendees: the PredictD Study. Arch Gen Psychiatry 65:1368-1376. https://doi. org/10.1001/archpsyc.65.12.1368

22. Nigatu YT, Liu Y, Wang J (2016) External validation of the international risk prediction algorithm for major depressive episode in the US general population: the PredictD-US study. BMC Psychiatry 16:256. https://doi.org/10.1186/s12888-016-0971-x

23. Wang J, Sareen J, Patten S, Bolton J, Schmitz N, Birney A (2014) A prediction algorithm for first onset of major depression in the general population: development and validation. J Epidemiol Community Health 68:418-424. https://doi.org/10.1136/jech2013-202845

24. Christensen MC, Mayer SA, Ferran JM, Kissela B (2009) Depressed mood after intracerebral hemorrhage: the FAST trial. Cerebrovasc Dis 27:353-360. https://doi.org/10.1159/000202012

25. Covic T, Adamson B, Spencer D, Howe G (2003) A biopsychosocial model of pain and depression in rheumatoid arthritis: a 12-month longitudinal study. Rheumatology 42:1287-1294. https ://doi.org/10.1093/rheumatology/keg369

26. de Man-van Ginkel JM, Hafsteinsdóttir TB, Lindeman E, Ettema RGA, Grobbee DE, Schuurmans MJ (2013) In-hospital risk prediction for post-stroke depression. Stroke 44:2441-2445. https:// doi.org/10.1161/STROKEAHA.111.000304

27. Levin HS, McCauley SR, Josic CP, Boake C, Brown SA, Goodman HS, Merritt SG, Brundage SI (2005) Predicting depression following mild traumatic brain injury. Arch Gen Psychiatry 62:523-528. https://doi.org/10.1001/archpsyc.62.5.523

28. ten Doesschate MC, Bockting CL, Koeter MW, Schene AH, Group DS (2010) Prediction of recurrence in recurrent depression: a 5.5-year prospective study. J Clin Psychiatry 71:984-991. https://doi.org/10.4088/JCP.08m04858blu

29. Wang JL, Patten S, Sareen J, Bolton J, Schmitz N, MacQueen G (2013) Development and validation of a prediction algorithm for use by health professionals in prediction of recurrence of major depression. Depress Anxiety 31:451-457. https://doi.org/10.1002/ da. 22215

30. Van Voorhees BW, Paunesku D, Gollan J, Kuwabara S, Reinecke M, Basu A (2008) Predicting future risk of depressive episode in adolescents: the Chicago Adolescent Depression Risk Assessment (CADRA). Ann Fam Med 6:503-511. https://doi.org/10.1370/ afm. 887

31. Rocha TB, Fisher HL, Anselmi L, Arseneault L, Barros FC, Caspi A, Caye A, Danese A, Gonçalves H, Harrington H, Houts R, Menezes AMB, Moffitt TE, Mondelli V, Poulton R, Rohde LA, Wehrmeister F, Kieling C (2020) Identifying adolescents at risk for depression: a prediction score performance in cohorts based in three different continents. J Am Acad Child Adolesc Psychiatry. https://doi.org/10.1016/j.jaac.2019.12.004

32. United Nations Development Programme (2018) Human development indicators-Nepal: poverty. https://hdr.undp.org/en/countries/ profiles/NPL. Accessed 13 Jun 2019

33. INSEC (2008) Fact sheet: number of victims killed by state and Maoist in connection with the "People's War" (12 Feb 1996-31 Dec 2006). Informal Sector Service Center, Kathmandu

34. Central Bureau of Statistics-National Planning Commission Secretariat, Government of Nepal, United Nations Development Programme (2016) Annual Household Survey 2015/2016 major findings. https://nada.cbs.gov.np/index.php/catalog/85. Accessed 15 Aug 2019

35. Human Rights Watch (2007) Children in the ranks: the Maoists' use of child soldiers in Nepal. https://hrw.org/reports/2007/nepal 0207/. Accessed 5 Jul 2019 
36. United Nations (2006) Report of the Secretary-General on children and armed conflict in Nepal. https://www.un.org/ga/search/ view_doc.asp?symbol=S/2006/1007\&Lang=E\&Area=UNDOC . Accessed 15 Aug 2019

37. Kohrt BA, Jordans MJ, Tol WA, Speckman RA, Maharjan SM, Worthman CM, Komproe IH (2008) Comparison of mental health between former child soldiers and children never conscripted by armed groups in Nepal. JAMA 300:691-702. https://doi. org/10.1001/jama.300.6.691

38. Bhardwaj A, Bourey C, Rai S, Adhikari RP, Worthman CM, Kohrt BA (2018) Interpersonal violence and suicidality among former child soldiers and war-exposed civilian children in Nepal. Glob Ment Health 5:e9. https://doi.org/10.1017/gmh.2017.31

39. Kohrt BA, Burkey M, Stuart EA, Koirala S (2015) Alternative approaches for studying humanitarian interventions: propensity score methods to evaluate reintegration packages impact on depression PTSD, and function impairment among child soldiers in Nepal. Glob Ment Health 2:e16. https://doi.org/10.1017/ gmh.2015.13

40. Kohrt BA, Jordans MJ, Koirala S, Worthman CM (2015) Designing mental health interventions informed by child development and human biology theory: a social ecology intervention for child soldiers in Nepal. Am J Hum Biol 27:27-40. https://doi. org/10.1002/ajhb.22651

41. Kohrt BA, Worthman CM, Adhikari RP, Luitel NP, Arevalo JMG, Ma J, McCreath H, Seeman TE, Crimmins EM, Cole SW (2016) Psychological resilience and the gene regulatory impact of posttraumatic stress in Nepali child soldiers. Proc Natl Acad Sci USA 113:8156-8161. https://doi.org/10.1073/pnas.1601301113

42. Adhikari RP, Kohrt BA, Luitel NP, Upadhaya N, Gurung D, Jordans MJD (2014) Protective and risk factors of psychosocial wellbeing related to the reintegration of former child soldiers in Nepal. Intervent J Ment Health Psychosoc Supp Confl Affect Areas 12:367-378. https://doi.org/10.1097/WTF.0000000000 000056

43. Birleson P (1981) The validity of depressive disorder in childhood and the development of a self-rating scale: a research report. J Child Psychol Psychiatry 22:73-88. https://doi. org/10.1111/j.1469-7610.1981.tb00533.x

44. Kohrt BA, Jordans MJD, Tol WA, Luitel NP, Maharjan SM, Upadhaya N (2011) Validation of cross-cultural child mental health and psychosocial research instruments: adapting the Depression SelfRating Scale and Child PTSD Symptom Scale in Nepal. BMC Psychiatry 11:127. https://doi.org/10.1186/1471-244X-11-127

45. Goncalves H, Assuncao MC, Wehrmeister FC, Oliveira IO, Barros FC, Victora CG, Hallal PC, Menezes AM (2014) Cohort profile update: the 1993 Pelotas (Brazil) birth cohort follow-up visits in adolescence. Int J Epidemiol 43:1082-1088. https://doi. org/10.1093/ije/dyu077

46. Kohrt BA, Speckman RA, Kunz RD, Baldwin JL, Upadhaya N, Acharya NR, Sharma VD, Nepal MK, Worthman CM (2009) Culture in psychiatric epidemiology: using ethnography and multiple mediator models to assess the relationship of caste with depression and anxiety in Nepal. Ann Hum Biol 36:261-280. https://doi. org/10.1080/03014460902839194

47. StataCorp (2017) Stata statistical software: release 15. StataCorp LLC, College Station

48. R Core Team (2019) R: a language and environment for statistical computing. R Foundation for Statistical Computing, Vienna, Austria. https://www.R-project.org/

49. Steyerberg EW, Borsboom GJ, van Houwelingen HC, Eijkemans MJ, Habbema JD (2004) Validation and updating of predictive logistic regression models: a study on sample size and shrinkage. Stat Med 23:2567-2586. https://doi.org/10.1002/sim.1844

50. Steyerberg EW, Moons KGM, Vergouwe Y (2010) External validity of risk models: use of benchmark values to disentangle a case-mix effect from incorrect coefficients. Am J Epidemiol 172:971-980. https://doi.org/10.1093/aje/kwq223

51. Pencina MJ, Steyerberg EW, D’Agostino RB Sr (2017) Net reclassification index at event rate: properties and relationships. Stat Med 36:4455-4467. https://doi.org/10.1002/sim.7041

52. Steyerberg EW, Vickers AJ, Cook NR, Gerds T, Gonen M, Obuchowski N, Pencina MJ, Kattan MW (2010) Assessing the performance of prediction models: a framework for traditional and novel measures. Epidemiol 21:128-138. https://doi.org/10.1097/ EDE.0b013e3181c30fb2

53. Fenlon C, O'Grady L, Doherty ML, Dunnion J (2018) A discussion of calibration techniques for evaluating binary and categorical predictive models. Prev Vet Med 149:107-114. https://doi. org/10.1016/j.prevetmed.2017.11.018

54. Hosmer DW, Lemeshow S, Sturdivant RX (2013) Applied logistic regression, 3rd edn. Wiley, Hoboken

55. Brier GW (1950) Verification of forecasts expressed in terms of probability. Mon Weather Rev 78:1-3. https://doi. org/10.1175/1520-0493(1950)078\%3c0001:VOFEIT\%3e2.0.CO;2

56. Luitel NP, Jordans MJD, Adhikari A, Upadhaya N, Hanlon C, Lund C, Komproe IH (2015) Mental health care in Nepal: current situation and challenges for development of a district mental health care plan. Confl Health. https://doi.org/10.1186/s1303 1-014-0030-5

57. Thapaliya S, Sharma P, Upadhyaya K (2018) Suicide and self harm in Nepal: a scoping review. Asian J Psychiatry 32:20-26. https://doi.org/10.1016/j.ajp.2017.11.018

58. Mokdad AH, Forouzanfar MH, Daoud F, Mokdad AA, El Bcheraoui C, Moradi-Lakeh M, Kyu HH, Barber RM, Wagner J, Cercy K, Kravitz H, Coggeshall M, Chew A, O'Rourke KF, Steiner C, Tuffaha M, Charara R, Al-Ghamdi EA, Adi Y, Afifi RA, Alahmadi H, AlBuhairan F, Allen N, AlMazroa M, Al-Nehmi AA, AlRayess Z, Arora M, Azzopardi P, Barroso C, Basulaiman M, Bhutta ZA, Bonell C, Breinbauer C, Degenhardt L, Denno D, Fang J, Fatusi A, Feigl AB, Kakuma R, Karam N, Kennedy E, Khoja AM, Maalouf F, Obermeyer CM, Mattoo A, McGovern T, Memish ZA, Mensah GA, Patel V, Petroni S, Reavley N, Zertuche DR, Saeedi M, Santelli J, Sawyer SM, Ssewamala F, Taiwo K, Tantawy M, Viner RM, Waldfogel J, Zuñiga MP, Naghavi M, Wang H, Vos T, Lopez AD, Al Rabeeah AA, Patton GC, Murray CJL (2016) Global burden of diseases, injuries, and risk factors for young people's health during 1990-2013: a systematic analysis for the Global Burden of Disease Study (2013). Lancet 387:2383-2401. https://doi.org/10.1016/S0140-6736(16)00648-6

59. Kohrt BA, Hruschka DJ (2010) Nepali concepts of psychological trauma: the role of idioms of distress, ethnopsychology and ethnophysiology in alleviating suffering and preventing stigma. Cult Med Psychiatry 34:322-352. https://doi.org/10.1007/s1101 3-010-9170-2

60. Rai S, Adhikari SB, Acharya NR, Kaiser BN, Kohrt BA (2017) Elucidating adolescent aspirational models for the design of public mental health interventions: a mixed-method study in rural Nepal. Child Adolesc Psychiat Ment Health. https://doi. org/10.1186/s13034-017-0198-8

61. Gautam K, Pedersen G, Wahid S, Kohrt BA (2019) Ethical considerations for conducting cross-cultural biological psychiatry and prevention research on depression among adolescents in low-and middle-income countries. In: Raddin J, Cratsley K (eds) DNB 2: mental health as public health: interdisciplinary perspectives on the ethics of prevention. Elsevier, New York

62. Lawrie SM, Fletcher-Watson S, Whalley HC, McIntosh AM (2019) Predicting major mental illness: ethical and practical considerations. BJPsych Open 5:e30. https://doi.org/10.1192/ bjo.2019.11 


\section{Affiliations}

\section{Rachel Brathwaite ${ }^{1}$ Thiago Botter-Maio Rocha ${ }^{2,3} \cdot$ Christian Kieling $^{2,3} \cdot$ Kamal Gautam $^{4}$. Suraj Koirala ${ }^{4}$.} Valeria Mondelli ${ }^{5} \cdot$ Brandon Kohrt $^{4,6} \cdot$ Helen L. Fisher $^{1}$ (i)

1 Social Genetic and Developmental Psychiatry Centre, Institute of Psychiatry, Psychology and Neuroscience, King's College London, 16 De Crespigny Park, London SE5 8AF, UK

2 Department of Psychiatry, Universidade Federal Do Rio Grande Do Sul, Porto Alegre, Brazil

3 Child and Adolescent Psychiatry Division, Hospital de Clínicas de Porto Alegre, Porto Alegre, Brazil
4 Transcultural Psychosocial Organization Nepal (TPO Nepal), Kathmandu, Nepal

5 Department of Psychological Medicine, Institute of Psychiatry, Psychology and Neuroscience, King's College London, London, UK

6 Division of Global Mental Health, George Washington University, Washington, DC, USA 